\title{
A dicotomia do Princípio da Integralidade do SUS
}

\author{
The SUS Completeness principle of dichotomy
}

La dicotomia del Principio de la Integralidad del SUS

Lisiane Rodrigues Alves ${ }^{1}$

\begin{abstract}
RESUMO: Este artigo tem como objetivo discutir o aspecto dicotômico do princípio da integralidade, a partir de uma revisão literária narrativa. Apresenta um breve mapeamento histórico da luta pela saúde no mundo e no Brasil, como uma prática social. O princípio da integralidade como forma de ampliação ao acesso à saúde e, também, como forma de sua restrição. Finalizando com a análise das tentativas de arrefecimento desta dicotomia em contraste com a realidade social e econômica da sociedade brasileira.
\end{abstract}

Palavras-chave: Dicotomia. Integralidade. Saúde

ABSTRACT: This article aims to discuss the dichotomous aspect of the integrality principle, based on a literary narrative review. It presents a brief historical mapping of the struggle for health in the world and in Brazil, as a social practice. The principle of integrality as a way of expanding access to health and, also, as a form of its restriction. Finalizing with the analysis of attempts to cool this dichotomy in contrast to the social and economic reality of Brazilian society.

Keywords: Dichotomy. Integrality. Health

RESUMEN: Este artículo tiene como objetivo discutir el aspecto dicotómico del principio de LA exhaustividad, a partir de una revisión narrativa literaria. Se presenta una historia de la lucha de la salud en el mundo y en Brasil, como una práctica social. El principio de la integralidad como medio para ampliar el acceso a la salud y también como una forma de restringir ellos. Al final con el análisis de esta dicotomía en contraste con la realidad social y económica de la sociedad brasileña.

Palabras-Ilave: Dicotomia. Integralidad. Salud

\section{Introdução}

A construção do SUS, uma das características fundamentais do sistema, é uma inédita e radical politização do que, tradicionalmente, consideram procedimentos técnicooperacionais do planejamento e organização, sendo que o cenário que se apresenta é de superação da tradicional separação entre a esfera política e a técnica, na qual as ações tomam os espaços de gestão concreta das redes de serviços e de operação do instrumental próprio das políticas públicas, o que vem exigindo novos padrões de relacionamento entre

\footnotetext{
${ }_{1}^{1}$ Advogada, Assessora Jurídica da Secretaria Estadual da Saúde do Rio Grande do Sul, Especialista em Direito Sanitário pela Escola de Saúde Pública da SES/RS/ Unisinos. Email: lisianealves@terra.com.br
} 
serviços, profissionais e usuários (1).

Dentro desta realidade, em 1988, a Constituição da República Federativa do Brasil, trouxe o princípio da integralidade como um dos princípios norteadores do Sistema Único de Saúde ${ }^{2}$, vindo a ser definido legal e institucionalmente na NOB/96² como "um conjunto articulado de ações e serviços de saúde, preventivos, curativos, individuais e coletivos em cada caso, nos níveis de complexidade do sistema".

Ou seja, é um marcador contínuo que se estrutura a partir de uma ação social específica, que pode incluir os aspectos objetivos e subjetivos da interação/relação dos atores em suas práticas no interior das instituições (3).

Dessa maneira, a integralidade é um conceito que permite a identificação dos sujeitos como totalidades, ainda que não sejam alcançáveis em sua plenitude, considerando todas as dimensões possíveis que se pode intervir, pelo acesso permitido por eles próprios (4).

\section{Metodologia}

A metodologia aplicada foi a revisão da literatura que:

É o processo de busca, análise e descrição de um corpo do conhecimento em busca de resposta a uma pergunta específica. "Literatura" cobre todo o material relevante que é escrito sobre um tema: livros, artigos de periódicos, artigos de jornais, registros históricos, relatórios governamentais, teses e dissertações e outros tipos". (5)

Sendo que esta metodologia possui três tipos (6):

a) Narrativa - não utiliza critérios explícitos e sistemáticos para a busca e análise crítica da literatura. A busca pelos estudos não precisa esgotar as fontes de informações. Não aplica estratégias de busca sofisticadas e exaustivas. A seleção dos estudos e a interpretação das informações podem estar sujeitas à subjetividade dos autores. É adequada para a fundamentação teórica de artigos, dissertações, teses, trabalhos de conclusão de cursos.

b) Sistemática - é um tipo de investigação científica. Essas revisões são consideradas estudos observacionais retrospectivos ou estudos experimentais de recuperação e análise crítica da literatura. Testam hipóteses e têm como objetivo levantar, reunir, avaliar

\footnotetext{
2 Art. 198. As ações e serviços públicos de saúde integram uma rede regionalizada e hierarquizada e constituem um sistema único, organizado de acordo com as seguintes diretrizes:

II - atendimento integral, com prioridade para as atividades preventivas, sem prejuízo dos serviços assistenciais.
} 
criticamente a metodologia da pesquisa e sintetizar os resultados de diversos estudos primários. Busca responder a uma pergunta de pesquisa claramente formulada. Utiliza métodos sistemáticos e explícitos para recuperar, selecionar e avaliar os resultados de estudos relevantes. Reúne e sistematiza os dados dos estudos primários (unidades de análise). É considerada a evidência científica de maior grandeza e são indicadas na tomada de decisão na prática clínica ou na gestão pública.

c) Integrativa - surgiu como alternativa para revisar rigorosamente e combinar estudos com diversas metodologias, por exemplo, delineamento experimental e não experimental, e integrar os resultados. Tem o potencial de promover os estudos de revisão em diversas áreas do conhecimento, mantendo o rigor metodológico das revisões sistemáticas. O método de revisão integrativa permite a combinação de dados da literatura empírica e teórica que podem ser direcionados à definição de conceitos, identificação de lacunas nas áreas de estudos, revisão de teorias e análise metodológica dos estudos sobre um determinado tópico. A combinação de pesquisas com diferentes métodos combinados na revisão integrativa amplia as possibilidades de análise da literatura.

Sendo que, para este trabalho, se adequou a revisão narrativa, pois constitui, basicamente, de análise da literatura publicada em livros, artigos de revista impressas e/ou eletrônicas na interpretação e análise crítica pessoal do autor.

Essa categoria de artigos têm um papel fundamental para a educação continuada pois, permitem ao leitor adquirir e atualizar o conhecimento sobre uma temática específica em curto espaço de tempo; porém não possuem metodologia que permitam a reprodução dos dados e nem fornecem respostas quantitativas para questões específicas. São considerados artigos de revisão narrativas e são qualitativos (7).

\section{Resultados}

A - Conceito de integralidade

Para se conseguir compreender ou até mesmo visualizar a conceituação do princípio da integralidade, um dos princípios norteadores do Sistema Único de Saúde (SUS) no Brasil, é necessária, senão obrigatória, a realização de um breve mapeamento histórico da luta pela saúde, no mundo e no Brasil, como uma prática social.

Assim, divide-se em três períodos distintos:

a) Século XVI ao XVIII; 
b) Século XIX;

c) Século $X X$.

O período renascentista (a) foi marcado pela modificação de costumes e idéias, provocando uma profunda alteração no comportamento político, cultural e econômico da Europa, cujo período foi do século XVI ao século XVIII, como bem destaca Luz (8):

(...)ao mesmo tempo uma época de modificação de costumes e idéias, e uma série de momentos inaugurais na criação artística e filosófica, científica e tecnológica, que têm ressonância progressiva, a partir de centros urbanos de irradiação, para todo o mundo conhecido (Velho Mundo). Essa ressonância produz uma série de mudanças profundas no comportamento político, cultural e econômico da Europa, cujos efeitos de mutação se fizeram sentir até o século XVIII.

Importante referir que na segunda metade do século XVIII, na Europa Ocidental, surgiram as bases doutrinárias acerca da saúde em um processo histórico de disciplinamento dos corpos e constituição das intervenções sobre os sujeitos (9).

Nesse período a abordagem acerca da saúde possuía dois aspectos: de um lado a higiene, como um conjunto de preceitos a serem seguidos pelo indivíduo isoladamente, de outro, as propostas de uma política ou polícia médica, em que o Estado assume a responsabilidade de definidor de políticas, leis e regulamentos relativamente à saúde no coletivo e, respectivamente, como seu fiscalizador da aplicação social respectiva.

Dessa maneira, as práticas de saúde foram remetidas ao plano jurídico-político, ou seja, a racionalidade moderna coincide com a racionalidade científica, quando toma como norma epistêmica a utilização de um método de produção de verdades como meio de legitimação perante a sociedade, através do exercício contínuo e renovado de "buscar novos conteúdos de verdades" (pesquisa científica) (8).

No século XIX (b) o grande fator que marcou a organização da massa trabalhadora, marcadamente na Inglaterra, França e Alemanha, foi a Revolução Industrial, passando, a saúde, a ser uma das reivindicações sociais no período de 1830 e 1880.

Assim, passou-se a compreender a crise sanitária como um processo político e social denominado Medicina Social, em que se postulou a aplicação da medicina no âmbito social curando-se os males da sociedade.

Neste mesmo período surge na Inglaterra e nos Estados Unidos o movimento conhecido como sanitarismo, composto por funcionários das, recém implantadas, agências 
oficiais de saúde e bem-estar.

Os sanitaristas produzem um discurso e uma prática sobre as questões da saúde fundamentalmente baseadas em aplicações de tecnologia e em princípios de organização racional para a expansão de atividades profiláticas, destinadas, principalmente, aos pobres e setores excluídos da população.

Reforçando o movimento sanitarista, advém o paradigma microbiano nas ciências básicas de saúde e, praticamente, redefine as diretrizes da teoria e prática no campo da saúde social no mundo ocidental.

A racionalidade médica terá, na modernidade, a doença como categoria central, norteando, até os dias atuais, seu modo de intervenção na sociedade (8).

Já no século XX (c), houve uma sucessão de alterações e progressos, em razão das modificações do panorama político e social do mundo e da situação de saúde põem em cheque as premissas e previsões dos antigos modelos, tais alterações, para melhor visualização, passa-se a demonstrar na tabela abaixo organizada por período (década) e fato relevante:

\begin{tabular}{|c|l|}
\hline Período (década) & \multicolumn{1}{c|}{ Fato relevante } \\
\hline $\begin{array}{c}\text { Início do século } \\
\text { Décadas de } \\
10 \text { a } 30\end{array}$ & $\begin{array}{l}\text { Relatório Flexner (USA) - provoca uma profunda reavaliação das bases } \\
\text { científicas da medicina, que resulta na redefinição do ensino e da prática } \\
\text { médica a partir dos princípios tecnológicos rigorosos. Com sua ênfase no } \\
\text { conhecimento experimental de bases subindividual, esse modelo reforça a } \\
\text { separação entre individual e coletivo, privado e público, biológico e social, } \\
\text { curativo e preventivo. Surgindo as primeiras escolas de saúde pública, tal } \\
\text { como a Fundação Rockefeller, inicialmente nos USA e, posteriormente, na } \\
\text { América Latina. }\end{array}$ \\
\hline Década de 40 & $\begin{array}{l}\text { Ao lado de reflexos sociais da crise econômica de 29 e, também, o } \\
\text { incremento dos custos em razão da especialização e da tecnologização da } \\
\text { prática médica, articula-se nos USA propostas de implantação de um } \\
\text { sistema nacional de saúde, propõe-se a abertura de departamentos de } \\
\text { medicina preventiva, nos moldes da maioria dos países europeus. }\end{array}$ \\
\hline Década de 50 & $\begin{array}{l}\text { 1952 - Realização em Colorado Springs de uma reunião de importantes } \\
\text { escolas de medicina norte-americanas, propondo-se ampla reforma dos } \\
\text { currículos médicos no sentido de inculcar uma atitude preventiva nos futuros } \\
\text { praticantes, redefinido-se, radicalmente, a noção de prevenção, constituindo } \\
\text { "dilema preventista"10. Com entusiasmo os organismos internacionais do } \\
\text { campo da saúde aderiram, realizando-se congressos similares ao de } \\
\text { Colorado Springs em Nancy (França) no mesmo ano; em 1953 em } \\
\text { Gotemburgo (Suécia), patrocinado pela OMS }{ }^{3}, \text { e na América Latina, sob o } \\
\text { patrocínio da OPS }{ }^{4} \text {, foram organizados seminários, em 1955, Viña Del Mar }\end{array}$ \\
\hline
\end{tabular}

${ }^{3}$ OMS - Organização Mundial de Saúde

${ }^{4}$ OPS - Organização Panamericana de Saúde 


\begin{tabular}{|c|c|}
\hline & $\begin{array}{l}\text { (Chile) e Tehuacán (México) em } 1956 . \\
\text { 1953- Definição de serviços básicos de saúde pela OMS, cobrindo as } \\
\text { seguintes atividades: a) atenção à saúde da mulher e da criança; b) controle } \\
\text { de doenças transmissíveis; c) saneamento ambiental; d) manutenção dos } \\
\text { sistemas de informação; e) educação em saúde; f)assistência médica de } \\
\text { baixo grau de complexidade. }\end{array}$ \\
\hline Década de 60 & $\begin{array}{l}1963 \text { - Uma comissão de especialistas propõe a inclusão nos serviços } \\
\text { básicos de saúde a participação. } \\
\text { Na América Latina, programas de saúde comunitária são implantados, } \\
\text { principalmente na Colômbia, no Brasil e no Chile, sob o patrocínio de } \\
\text { fundações norte-americanas e endossados pela OPS, na expectativa de que } \\
\text { o seu efeito-demonstração poderia influenciar positivamente o desenho dos } \\
\text { sistemas de saúde no continente. }\end{array}$ \\
\hline Década de 70 & $\begin{array}{l}1974 \text { - No Canadá, o Relatório Lalonde define as } 04 \text { (quatro) bases de um } \\
\text { movimento pela promoção da saúde, estabelecendo o modelo do "campo da } \\
\text { saúde": a) a biologia humana; b) o sistema de organização dos serviços; c) } \\
\text { o ambiente e d)o estilo de vida. Passou a se chamar de "revolution tranquile", } \\
\text { implantou-se em diversas províncias do Canadá uma rede de centros } \\
\text { comunitários de saúde e serviços sociais, efetivamente integrados a um } \\
\text { sistema de medicina socializada, que representa uma síntese dos modelos } \\
\text { de atenção precedentes. Sendo a Carta de Ottawa o documento oficial que } \\
\text { institucionaliza o modelo canadense, define os principais elementos } \\
\text { discursivos do movimento da promoção de saúde: a) integração da saúde } \\
\text { como parte das políticas públicas "saudáveis"; b) atuação da comunidade na } \\
\text { gestão do sistema; c) reorientação dos sistemas de saúde e d) ênfase na } \\
\text { mudança dos estilos de vida. } \\
1977 \text { - AAssembléia Mundial da Saúde lança a consigna Saúde para Todos } \\
\text { no Ano } 2000 \text { (SPT-2000), assumindo uma proposta política de extensão da } \\
\text { cobertura dos serviços básicos de saúde com base nos sistemas } \\
\text { simplificados de assistência à saúde. } \\
\text { 1978- Em Alma Ata, a Conferência Internacional sobre Atenção Primária à } \\
\text { Saúde, promovida pela OMS } \text {, reafirma a saúde como direito do homem sob } \\
\text { a responsabilidade política dos governos, e reconhece a sua determinação } \\
\text { intersetorial e, também, estabelece a Atenção Primária à Saúde como } \\
\text { estratégia privilegiada de operacionalização da SPT - 2000. }\end{array}$ \\
\hline Década de 80 & $\begin{array}{l}\text { Início da década de } 80-\text { o movimento de } 1978 \text { aparece com o rótulo } \\
\text { atualizado denominado SILOS }{ }^{6} \text { e dentro de um modelo distritalizado com } \\
\text { base em níveis hierarquizados de atenção, a retórica da saúde comunitária } \\
\text { integra-se às primeiras iniciativas de reforma setorial da saúde nos países } \\
\text { subdesenvolvidos; } \\
\text { Nos USA aparece um movimento inspirado na Carta de Otawa, sob a sigla } \\
\text { de HPDP }{ }^{7} \text {, indicando a opção pela proposta mínima de mudança de estilo } \\
\text { de vida por meio de programas de modificação de comportamentos } \\
\text { considerados de risco, como hábito de fumar, dieta, sedentarismo. } \\
1986-\text { a OMS absorveu este movimento lançando o Projeto Cidades } \\
\text { Saudáveis. } \\
1987 \text { a 1988- por iniciativa da OPS procedeu-se à análise da infraestrutura } \\
\text { privilegiando as seguintes áreas críticas: políticas públicas, sistemas de }\end{array}$ \\
\hline
\end{tabular}

${ }^{5}$ OMS - Organização Mundial de Saúde

6 SILOS - Sistemas Locais de Saúde

${ }^{7}$ HPDP - Health Promotion Disease Prevention 


\begin{tabular}{|c|c|}
\hline & $\begin{array}{l}\text { informação e desenvolvimento da epidemiologia, economia e financiamento, } \\
\text { recursos humanos em saúde, desenvolvimento tecnológico e sistemas de } \\
\text { serviços de saúde. } \\
1989 \text { e } 1990 \text { - foram realizados seminários para a análise da prestação de } \\
\text { serviços no que diz respeito a recuperação da saúde, prevenção de doenças } \\
\text { e promoção da saúde. }\end{array}$ \\
\hline Década de 90 & $\begin{array}{l}1991 \text { a 1995- a OPS encaminhou um ambicioso projeto para reflexão e } \\
\text { crítica sobre a teoria e a prática da saúde pública, tendo como referência os } \\
\text { textos básicos e a reunião do "Grupo de Consulta" ocorrida em New Orleans } \\
\text { em } 1991 . \\
1991 \text { - O Banco Mundial patrocina a atualização dos princípios do movimento } \\
\text { da promoção da saúde, nele incorporando a questão do desenvolvimento } \\
\text { econômico e social sustentado como importante pauta extra-setorial para o } \\
\text { campo da saúde; } \\
\text { 1992-A Conferência Mundial pelo Meio Ambiente, conhecida como ECo 92, } \\
\text { realizada no Rio de Janeiro, promovida pela ONU, a saúde ambiental foi } \\
\text { definida como prioridade social para a promoção da saúde, dentro da célebre } \\
\text { Agenda 21; } \\
1994 \text { - I Conferência Panamericana sobre Educação em Saúde Pública, Rio } \\
\text { de Janeiro, propôs o aprofundamento do debate em torno da transformação } \\
\text { da estrutura organizacional das respectivas escolas, considerando a } \\
\text { pertinência da desvinculação administrativa em relação às faculdades de } \\
\text { medicina; } \\
1995-\text { em Genebra, realizou-se um painel, convocado pela OMS, para } \\
\text { discutir a "Nova Saúde Pública", em consonância com as visões de } \\
\text { representantes europeus e americanos da saúde pública, não parece dar } \\
\text { conta dos impasses identificados na América Latina e Caribe, para eles a } \\
\text { crise não é estrutural e representaria apenas uma dada interpretação de } \\
\text { sanitaristas. Propõe uma agregação de novos temas e habilidades ao campo } \\
\text { da saúde pública ou ao seu âmbito de práticas e de instituições, elaborando } \\
\text { a "Renovação da Saúde para Todos (RSPT); } \\
\text { 1996 até } 2000 \text { - Definir e sustentar prioridades; destinar recursos para os } \\
\text { objetivos mais eficazes; inovar quando as velhas políticas fracassam; } \\
\text { coordenar metas conflitantes; impor perdas a grupos poderosos; representar } \\
\text { interesses difusos e desorganizados ao lado dos interesses mais } \\
\text { concentrados e bem organizados; garantir a execução dos programas; } \\
\text { assegurar a estabilidade dessas políticas, para que possam produzir efeitos; } \\
\text { estabelecer e manter compromissos internacionais, visando o bom } \\
\text { desenvolvimento a longo prazo; e sobretudo, administrar as clivagens } \\
\text { políticas, a fim de garantir que a sociedade não degenere em guerra civil. }\end{array}$ \\
\hline
\end{tabular}

Fonte: Alves, LR. O princípio da integralidade e as ações judiciais. Monografia apresentada no curso de Especialização em Direito Sanitário da Escola de Saúde Pública da Secretaria da Saúde do Estado do Rio Grande do Sul. 2010.

B - Integralidade e ampliação ao acesso à saúde

A integralidade em saúde é uma ação social que resulta da interação democrática entre

${ }^{8}$ ONU - Organização das Nações Unidas 
os atores no cotidiano de suas práticas na oferta do cuidado de saúde nos diferentes níveis de atenção do sistema da saúde.

Através do atendimento dos usuários de forma integral, deixa-se de enxergar apenas o organismo doente para analisar o ser humano como um todo, formando, com isso, uma Atenção Integral ao usuário, através da interação entre o tratamento, prevenção e promoção da saúde pública, realizando seu atendimento de forma multidisciplinar.

Diante dessa abordagem, a Promoção da Saúde é definida como o processo de capacitação da comunidade para atuar na melhoria da sua qualidade de vida e saúde, incluindo uma maior participação e controle desse processo (11).

Assim, a integralidade deve ser compreendida como um princípio que se alastra em vários níveis de discussão e das práticas na área da saúde, devendo, o gestor e o profissional, estar preparados para ouvir, entender e, a partir daí, atender às demandas e necessidades das pessoas, grupos e coletividades.

Um exemplo de abrangência deste princípio é a crescente incorporação de sistemas terapêuticos alternativos nos serviços públicos de saúde, como a utilização de fitoterápicos, evidencia uma compreensão ampliada do direito à saúde, na medida que os conteúdos teórico-práticos norteadores dessas práticas se aproximam da integralidade em duas dimensões: da atenção e do cuidado em saúde (12).

Importante destacar que a adesão as práticas terapêuticas alternativas, segundo estudiosos do sistema de saúde, é, também, uma das formas de garantir a universalização da assistência médica, por meio da garantia de escolha, pelo usuário, de seu tratamento, além de significar assegurar ao usuário o exercício da cidadania, temas estes que serão aprofundados em oportunidade futura.

Com isso, dentre as várias iniciativas de mudanças, pode-se referir como positiva a estratégia utilizada pelo Programa de Saúde da Família-PSF (13), surgida em 1994, com o propósito de mudança do modelo da atenção à saúde, que passa a ter como núcleo do cuidado às famílias, sendo as mesmas abordadas e compreendidas a partir do meio onde vivem.

Assim, dentre suas ações destaca-se o aspecto educativo, com o intuito de incentivar a autoestima e o cuidado dos membros da família, promovendo reflexões que conduzam a modificações nas atitudes e comportamentos, mas sua sustentabilidade depende do estabelecimento de parcerias intersetoriais, articulando-se ações interdisciplinares de 
assistência, prevenção e promoção da saúde.

Dessa maneira, para que o princípio da integralidade seja, efetivamente, exercido é necessário e essencial o trabalho em equipe transdisciplinar (8) entre os distintos saberes formais e não-formais, o que deve ocorrer desde a formação do profissional de saúde.

Com isso, uma educação em saúde nos moldes da integralidade inclui políticas pública $^{9}$, ambientes apropriados para além dos tratamentos clínicos e curativos, comprometidas com o desenvolvimento da solidariedade e da cidadania, envolvidas na melhoria da qualidade de vida e promoção do homem (14).

No contexto do Sistema Único de Saúde, a integralidade pode ser vista como uma imagem, uma noção amálgama, com vários sentidos (15):

a) crítica a atitude médica fragmentária - a um sistema que privilegia a especialização e segmentação, a atitude médica reducionista, a formação médica de base flexneriana, recusa em reduzir o paciente ao aparelho ou sistema biológico que supostamente produz o sofrimento e, portanto, a queixa do paciente, integralidade tomada a partir do referencial da Medicina Integral;

b) crítica a praticas dos profissionais de saúde - buscar compreender o conjunto de necessidades de ações e serviços de saúde que um paciente apresenta para além da atenção individual curativa, incorporação de ações de promoção e prevenção da atenção à saúde e articulação com as ações curativas e reabilitadoras - integralidade tomada a partir do referencial da Medicina Preventiva;

c) como modo de organizar as práticas - relaciona-se como a organização dos serviços e das práticas de saúde, crítica a separação entre práticas de saúde pública e práticas assistenciais, entre ações de saúde coletiva e atenção individual, crítica aos programas verticais - integralidade tomada como horizontalização dos programas;

d) como modo de organizar o processo de trabalho em saúde - otimizar o impacto epidemiológico, articular atenção a demanda espontânea como oferta programada de atenção à saúde, busca contínua de ampliar as possibilidades de apreensão e satisfação das necessidades de um grupo populacional, de ampliação da eficiência - integralidade tomada como oferta de programa de atenção à saúde;

\footnotetext{
9 Políticas Públicas compreendem um conjunto de decisões e ações direcionadas à solução de problemas políticos. Entende-se por atividades políticas, os procedimentos formais e informais que traduzem as relações de poder na sociedade. As políticas públicas buscam encontrar formas para resolver, sobretudo, os conflitos referidos a bens públicos (KEHRIG, Ruth Terezinha. Políticas Públicas. UNISUL Virtual, Palhoça, SC, 2006).
} 
e) como acesso às técnicas de diagnóstico e tratamento necessárias a caso a caso articulação a partir da atenção básica aos meios de diagnóstico e atenção especializada, quando necessário, de ampliação de acesso ao sistema de saúde e de resolutividade da atenção - integralidade tomada como acesso a diversos níveis de atenção;

f) como construção de políticas especificamente desenhadas - como forma de dar resposta a um determinado problema de saúde ou aos problemas de saúde que afligem um determinado grupo populacional, articulação intra e intersetorial, de ampliação dos âmbitos e articulação de diversos espaços para a busca de soluções, busca de qualidade de vida integralidade tomada como ampliação do horizonte de intervenção sobre problemas.

Diante disso, a integralidade do sistema está fundada em 03 (três) pilares que formam um todo indivisível: promoção, prevenção e recuperação. Logo, os serviços de saúde devem funcionar atendendo o indivíduo como um ser humano integral, submetido às mais deferentes situações de vida e de trabalho, ou seja, o atendimento deve ser realizado para a sua saúde e não somente para a sua doença, a fim de, com isso, erradicar as causas e diminuir os riscos, além de tratar os danos.

C - Integralidade e a restrição ao acesso à saúde

Assim, a integralidade é, simultaneamente, uma potencialidade e uma fragilidade, pois remete ao conceito de integração de serviços por meio de redes assistenciais necessárias para a solução dos problemas de saúde de uma população em seus diversos ciclos de vida e características sociais.

Dessa maneira, o sistema de saúde atende às pessoas que optaram pelo SUS, conforme prevê o princípio da universalidade, e estão inseridas nas Políticas Públicas, construídas para atender à coletividade, o que, muitas vezes, não está evidente aos olhos do indivíduo isolado, uma vez que estas referidas Políticas possuem etapas para sua elaboração (9), quais sejam:

Dessa maneira, está demonstrado que a construção da política pública de saúde, essencial para a efetivação da integralidade, é um processo dialético e democrático, derivado das reivindicações postas pelo movimento sanitário desde a década de 70 , como já demonstrado no item "A".

Ou seja, a integralidade é assumida como sendo uma ação social resultante da 
permanente interação dos atores na relação demanda e oferta, em planos distintos de atenção à saúde, nas quais os aspectos subjetivos e objetivos sejam considerados ${ }^{16}$, quais sejam:

A - Plano individual- onde se constroem a integralidade no ato da atenção individual

B - Plano sistêmico- onde se garante a integralidade das ações na rede de serviços.

Ou seja, o que caracteriza a integralidade é obviamente a apreensão ampliada das necessidades, mas principalmente essa habilidade de reconhecer a adequação das ofertas de ações de saúde ao contexto específico da situação no qual se dá o encontro do sujeito com a equipe de saúde (17). Trata-se mais de um exercício de seleção negociada do que é relevante para a construção de um projeto de intervenção ou terapêutico, capaz de dar, oportunamente, respostas ao conjunto de necessidades de ações e serviços de saúde.

Neste sentido, é importante destacar que a integralidade deve andar sempre acompanhada da prudência, uma vez que deve-se diferenciar a utilização indiscriminada de tecnologias de diagnóstico precoce, que apenas têm utilidade para expandir o consumo de bens e serviços, da utilização das mesmas tecnologias com a perspectiva de assegurar o direito do usuário do sistema público à saúde através de uma demanda programada para responder às necessidades coletivas, muitas vezes não percebida pelo indivíduo.

Saliente-se que o fator mais relevante para o aumento dos custos em saúde em todo o mundo, em particular nos Estados Unidos, é o contínuo progresso da tecnologia médica (18).

Com isso, a integralidade pode ser percebida como um princípio de organização contínua do processo de trabalho, conjugada com a busca de ampliação das possibilidades de apreensão das necessidades de saúde de um grupo populacional, o que podemos denominar de política de saúde.

Dessa forma, uma das divisões da Política Pública são os Programas de Saúde, que podem ser conceituados como um conjunto de ações organizadas com vista ao enfrentamento de um problema público qualquer, vinculados às Leis Orçamentárias e uma perspectiva de atuação não limitada temporalmente (19).

Neste ponto, revela-se a grande fragilidade da proposta do princípio da integralidade, uma vez que não se efetivaram encaminhamentos eficazes para seu financiamento, tornando-se subfinanciado, mesmo com a promessa constitucional de imposição de percentuais mínimos de aplicação das receitas dos entes federados, União, Estado, 
Municípios e Distrito Federal, art. $198, \S^{\circ}{ }^{\circ}$ da Constituição Federal ${ }^{10}$, acentuando o grau de restrição de acesso dos usuários à saúde pública. Com isso:

O baixo financiamento do SUS é hoje o fator que mais impossibilita os gestores municipais e estaduais de organizarem a oferta de serviços com qualidade, em consonância com as necessidades e direitos da população usuária. Os reflexos dessa situação provocam a sub-remuneração e precarização dos vínculos de trabalho dos profissionais e dos estabelecimentos prestadores de serviços, a ausência de investimento em melhores edificações e equipagem de unidades de saúde, colocando em risco a viabilidade da gestão" (20).

O legislador brasileiro tem consciência de tal situação, tanto que na própria Constituição Federal já previu em seu art. $196^{11}$,o acesso à saúde através de políticas públicas sociais e econômicas, ou seja, sempre se teve consciência de que a ação do Administrador Público deve estar pautada em planejamento social e financeiro, uma vez que os recursos advindos do erário sempre são escassos, face a infinitude das necessidades humanas de saúde, como desenvolvido no parágrafo anterior.

Além disso, o planejamento de todo o gasto público é obrigatório, também, pela Lei Complementar $n^{\circ} 101 / 2000^{12}$, como forma de aferir transparência à Administração, como também, previne a ocorrência de desvios de finalidade e, ainda, possibilita o equilíbrio das contas públicas ${ }^{13}$, valorando outros interesses da sociedade, que são complementares à saúde, tais como educação, esporte, lazer, meio ambiente, cultura, segurança e outros.

\footnotetext{
${ }^{10}$ Art. 198. As ações e serviços públicos de saúde integram uma rede regionalizada e hierarquizada e constituem um sistema único, organizado de acordo com as seguintes diretrizes:

$\S 2^{\circ} \mathrm{A}$ União, os Estados, o Distrito Federal e os Municípios aplicarão, anualmente, em ações e serviços públicos de saúde recursos mínimos derivados da aplicação de percentuais calculados sobre: (Incluído pela Emenda Constitucional $\mathrm{n}^{\circ}$ 29, de 2000)

I - no caso da União, na forma definida nos termos da lei complementar prevista no § $3^{\circ}$; (Incluído pela Emenda Constitucional $n^{\circ} 29$, de 2000)

II - no caso dos Estados e do Distrito Federal, o produto da arrecadação dos impostos a que se refere o art. 155 e dos recursos de que tratam os arts. 157 e 159, inciso I, alínea a, e inciso II, deduzidas as parcelas que forem transferidas aos respectivos Municípios; (Incluído pela Emenda Constitucional $n^{\circ} 29$, de 2000)

III - no caso dos Municípios e do Distrito Federal, o produto da arrecadação dos impostos a que se refere o art. 156 e dos recursos de que tratam os arts. 158 e 159, inciso I, alínea b e $\S 3^{\circ}$.(Incluído pela Emenda Constitucional $n^{\circ} 29$, de 2000).

${ }^{11}$ Art. 196. A saúde é direito de todos e dever do Estado, garantido mediante políticas sociais e econômicas que visem à redução do risco de doença e de outros agravos e ao acesso universal e igualitário às ações e serviços para sua promoção, proteção e recuperação.

${ }^{12}$ A LC 101/2000 estabelece normas de finanças públicas voltadas para a responsabilidade na gestão fiscal e dá outras providências

${ }^{13}$ LC 101/2000 : Art. $1^{\circ}$ Esta Lei Complementar estabelece normas de finanças públicas voltadas para a responsabilidade na gestão fiscal, com amparo no Capítulo II do Título VI da Constituição.

$\S 1^{\circ} \mathrm{A}$ responsabilidade na gestão fiscal pressupõe a ação planejada e transparente, em que se previnem riscos e corrigem desvios capazes de afetar o equilíbrio das contas públicas, mediante o cumprimento de metas de resultados entre receitas e despesas e a obediência a limites e condições no que tange a renúncia de receita, geração de despesas com pessoal, da seguridade social e outras, dívidas consolidada e mobiliária, operações de crédito, inclusive por antecipação de receita, concessão de garantia e inscrição em Restos a Pagar.
} 
Com isso, para se alcançar o princípio da integralidade é necessário identificar as prioridades dentro da área da saúde entre as diversas necessidades e políticas de saúde, o que sempre envolverá dificuldades distributivas e políticas também.

\section{Considerações finais}

Tenta-se diminuir a dicotomia existente no princípio da integralidade com a inclusão de novas tecnologias à saúde, com o acesso aos medicamentos fitoterápicos e com a regulamentação da Emenda Constitucional $n^{\circ} 29$, de 13 de setembro de 2000, através da Lei Complementar $n^{\circ} 141$, de 16 de janeiro de 2012, fixando-se os percentuais mínimos de investimento do orçamento público à saúde, como também, estabelecendo uma forma de transferência financeira menos burocratizada entre os entes públicos, através das denominadas transferências entre os fundos de saúde.

Ocorre que a perfeição do enunciado legal esbarra na dura realidade social e econômica vivenciada pelo Brasil há alguns anos, cujos cortes financeiros abalam a elaboração das políticas públicas de saúde e, consequentemente, a interdisciplinariedade necessária para a efetivação do princípio em discussão, tornando cada vez mais visível e enraizada a dicotomia existente.

\section{Referências}

1. Levcovitz, E. Transição X consolidação: o dilema estratégico da construção do SUS. Um estudo sobre as reformas das políticas de saúde - $1974-1996$. Tese (Doutorado em Saúde Coletiva) - Instituto de Medicina Social, Universidade do Estado do Rio de Janeiro, 1997.

2. Brasil: Ministério da Saúde. NOB - Norma Operacional Básica (Ministério da Saúde - NOB 96, 1996).

3. Bozi, M.L. Cidadania, participação e saúde na visão dos profissionais do setor de serviços. Um estudo de caso de rede pública de serviços. Cadernos de Saúde Pública, 10 (4): 446-456, 1994.

4. Nietsche EA. Tecnologia emancipatória: possibilidade para a práxis de enfermagem. ljui:Ed.Unijui; 2000.

5. Universidade Federal de São Paulo- UNESP - Campus de Botucatu. 20015. Disponível em www.fca.unesp.br/home/biblioteca/tipos-de-revisao-de-literatura.pdf. [Acesso em $1^{\circ}$.nov.2016]

6. Universidade de São Paulo - Instituto de Psicologia - Biblioteca Dante Moreira Leite. Diponível em www.ip.usp.br/portal/images/biblioteca/revisão.pdf. Acessado em 01/11/2016. 
7. Rother, E T. Revisão Sistemática X revisão narrativa. Disponível em www.scielo.br. Acessado em 01/11/2016.

8. Luz, M.T. Natural, racional e social. Razão médica e racionalidade científica moderna. Rio de Janeiro: Campus, 1988.

9. Paim, J. Almeida F. N. Saúde Coletiva: uma nova saúde pública ou campo aberto a novos paradigmas? Revista de Saúde Pública, 32 (4), 1998.

10. Arouca, A.S. O dilema preventista: contribuição para a compreensão e crítica da medicina preventiva. Campinas, 1975. Tese de Doutoramento - Universidade Estadual de Campinas.

11. Organização Mundial de Saúde-OMS. Carta de Ottawa. In: Promoção da Saúde e Saúde Pública. Rio de Janeiro: Escola Nacional de Saúde Pública. Fundação Oswaldo Cruz. 1986. p. 158-162.

12. Mendes, E.V. Uma agenda pra saúde. São Paulo: Hucitec, 1997.

13. Souza MF. O Programa Saúde da Família: uma visão nacional. In: Fernandes MEL, Dowbor TP, Kretzer MR, Gouveia I, Sucupira AC, Menezes L, Resegue R, organizadores. AIDS: prevenção porta a porta. São Paulo: Hucitec; 2004, p. 41-5.

14. Schall VT, Stuchiner M. Educação em Saúde: Novas Perspectivas. Caderno de Saúde Pública. 1999, 2:4-5.

15. Kell, Maria do Carmos Gomes. Integralidade da Atenção à Saúde. Disponível em: www.saude.gov.br. [Acesso em 13.jul.2009].

16. Pinheiro, Roseni; Mattos, Rubens A. Os sentidos da integralidade na atenção e no cuidado à saúde. Rio de Janeiro: ABRASCO, 2001.

17. Mattos, Rubens Araújo de. A Integralidade na prática (ou sobre a prática da integralidade. Caderno Saúde Pública, rio de Janeiro, 20(5): 1411-1416, set-out, 2004.

18. Amaral, Gustavo. Direto, Escassez \& Escolha, Editora Renovar, 2001, pag.142.

19. Mattos, Ruben Araújo de. Os Sentidos da Integralidade: algumas reflexões acerca dos valores que merecem ser defendidos 1. Disponível em: www.lappis.org.br. [Acesso em 13.jul.2009].

20. Centro Brasileiro de Estudos de Saúde-CEBES. Gastos em saúde: é muito ou é pouco? Disponível em www.cebes.org.br. [Acesso em 8.nov.2009].

Recebido em: 25.nov.2016

Aprovado em: 21.mar.2017

\section{Como citar este artigo:}

Alves LR. A dicotomia do Princípio da Integralidade do SUS. Revista Cadernos Ibero-Americanos de Direito Sanitário. 2017 jan./mar, 6(1):153-166. 